\title{
Demographic factors in hip fracture incidence and mortality rates in California, 2000-2011
}

\author{
Kristynn J. Sullivan', Lisa E. Husak², Maria Altebarmakian² and W. Timothy Brox ${ }^{3 *}$
}

\begin{abstract}
Background: Hip fractures result in both health and cost burdens from a public health perspective and have a major impact on the health care system in the USA. The purpose was to examine whether there were systematic differences in hip fracture incidence and 30-, 90-, and 365-day mortality after hip fracture in the California population as a function of age, gender, and race/ethnicity from 2000-2011.

Methods: This was a population-based study from 2000 to 2011 using data from the California Office of Statewide Health and Planning and Development (OSHPD, $N=317,677)$, California State Death Statistical Master File records $(N=224,899)$, and the US Census 2000 and 2010. There were a total of 317,677 hospital admissions for hip fractures over the 12-year span and 24,899 deaths following hip fractures. All participants without linkage (substituted for social security) numbers were excluded from mortality rate calculations. Variation in incidence and mortality rates across time, gender, race/ethnicity, and age were assessed using Poisson regression models. Odds ratio and $95 \%$ confidence intervals are provided.
\end{abstract}

Results: The incidence rate of hip fractures decreased between 2000 and 2011 (odds ratio (OR) = 0.98, $95 \%$ confidence interval $(\mathrm{Cl})$ 0.98, 0.98). Mortality rates also decreased over time. There were gender, race/ethnicity, and age group differences in both incidence and mortality rates.

Conclusions: Males were half as likely to sustain a hip fracture, but their mortality within a year of the procedure is almost twice the rate than women. As age increased, the prevalence of hip fracture increased dramatically, but mortality did not increase as steeply. Caucasians were more likely to sustain a hip fracture and to die within 1 year after a hip fracture. The disparities in subpopulations will allow for targeted population interventions and opportunities for further research.

Keywords: Hip fractures, Demographics, Incidence, Mortality, Age, Gender, Race/ethnicity

\section{Background}

Hip fractures have a major impact on the health care system in the USA with an estimated incidence of 340,000 fractures annually [1]. The annual economic burden of managing hip fractures was estimated at $\$ 17$ 20 billion in 2010 [1, 2]. As people are expected to live longer, hip fractures will become more common. It is estimated that by the year 2050 worldwide, there will be an estimated 6.3 million hip fractures worldwide [3]. Hip

\footnotetext{
*Correspondence: wtimbrox@gmail.com

${ }^{3}$ Orthopaedic Surgery, Kaiser Permanente Medical Center, 7300 N Fresno

Street, Fresno, CA 93720, USA

Full list of author information is available at the end of the article
}

fractures are a serious and life-changing event for an older person. Often after an initial hip fracture, a person cannot continue living independently and must undergo drastic lifestyle changes $[4,5]$. In addition, there is an association between hip fractures and an increase in mortality. One year mortality rate after a hip fracture is estimated between 17 and $27 \%$ [6-9].

The study has two primary hypotheses: first, that there are population factor variations in hip fracture incidence and, second, that there are systematic variations in mortality after hip fracture within the California population. A secondary hypothesis is that there has been a change in incidence trends over time from 2000 to 2011. 
Several factors may be associated with hip fracture incidence such as age, gender, and race/ethnicity $[1,10]$. California is a diverse state and provides an opportunity to examine these factors in relation to incidence of hip fracture and mortality following a hip fracture. The goal was to explore the effects of gender, age, and race/ ethnicity, with regard to the incidence of hip fracture and 30-, 90-, and 365-day mortality rates in California from 2000 to 2009.

In the recent era of increasing health care quality measurement, these population data and analysis will be helpful in the interpretation of patient hip fracture incidence and mortality outcomes [11].

\section{Methods}

This study was a population-based epidemiological review of all California Office of Statewide Health and
Planning and Development (OSHPD) non-federal hospital admissions for hip fractures from 2000 to 2011.

Mortality data was extracted from the California State Death Statistical Master File (DSMF) records. Participants were assigned a linkage number, similar to a de-identified social security number, and data from initial hospital admission OSHPD records were linked to DSMF records, if applicable (e.g., if death had occurred). This linking method has previously been explained in detail [12].

Participants were any patient 55 years and older admitted with the primary International Classification of Disease, 9th Revision (ICD-9) procedure code for the treatment of hip fractures. These include partial hip arthroplasty (ICD9 81.52), internal fixation of bone without fracture reduction (ICD-9 78.55), closed reduction of fracture with internal fixation (ICD-9 79.15), open

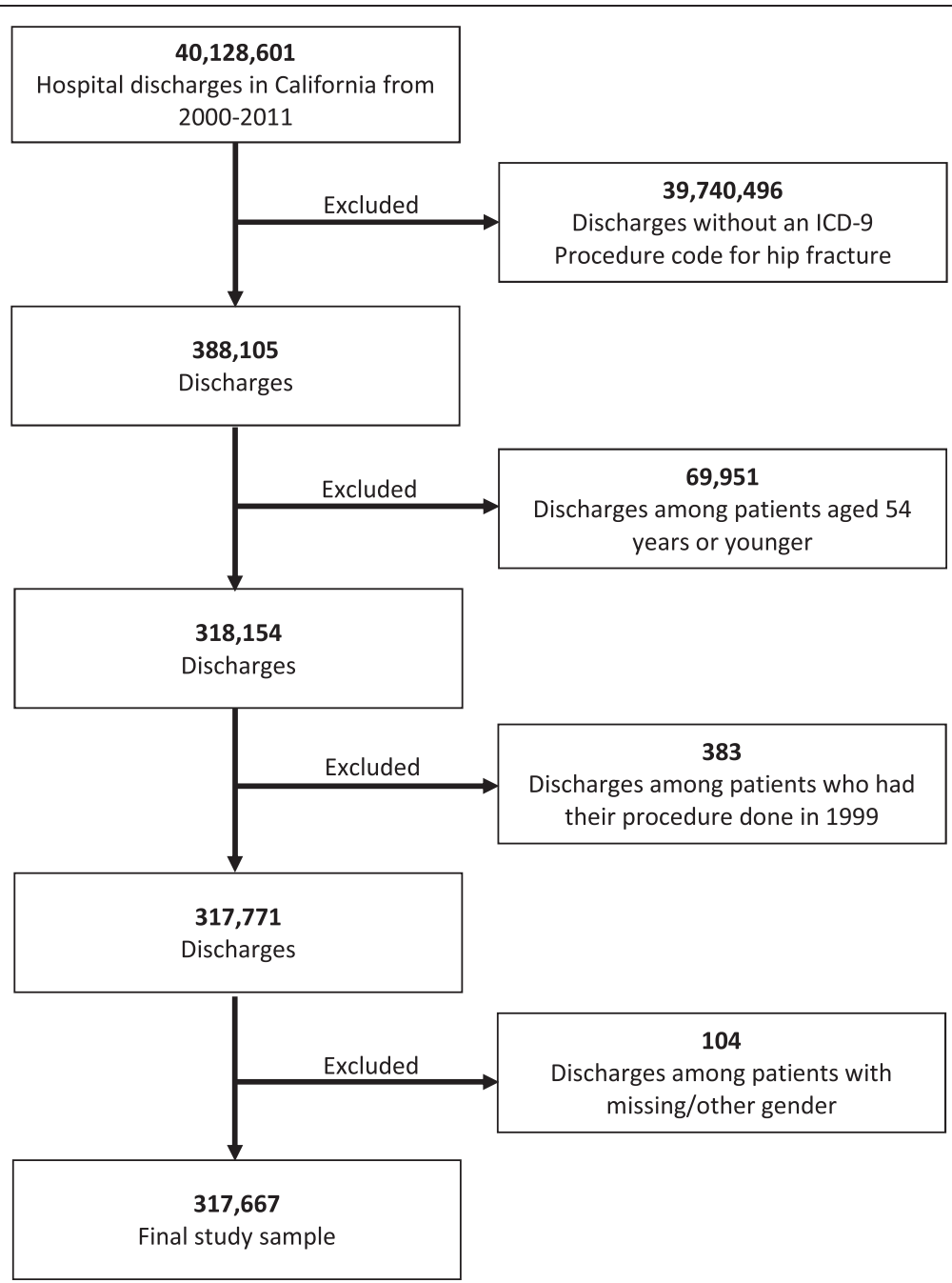

Fig. 1 Flow diagram to show the creation of the study sample for the incidence of hip fractures 
reduction of fracture with internal fixation, femur (ICD-9 79.35), and open reduction of separated epiphysis (ICD-9 79.55); see comments in study limitation section with regard to (ICD-9 79.55). There were a total of 317,677 hospital admissions for hip fractures over the 12-year span and 24,899 deaths following hip fractures (Figs. 1 and 2). All participants without linkage (substituted for social security) numbers were excluded from mortality rate calculations.

To evaluate the differences in the incidence of hip fracture, the outcome variable was incidence rate. To evaluate the difference in mortality, the outcome variables were 30-, 90-, and 365-day mortality. Hip fracture incidence rates were calculated based on hospital admission; a patient with multiple hip fractures could be counted twice toward hip fracture incidence rates.

Both incidences of hip fracture and mortality were evaluated by gender, age, race/ethnicity, and geographical area. Gender had two levels, male and female. Females were used as a reference group. Age was categorized in seven levels: 55-59, 60-64, 65-69, 70-74, $75-79,80-84$, and $85+$. The $65-69$ age group was used

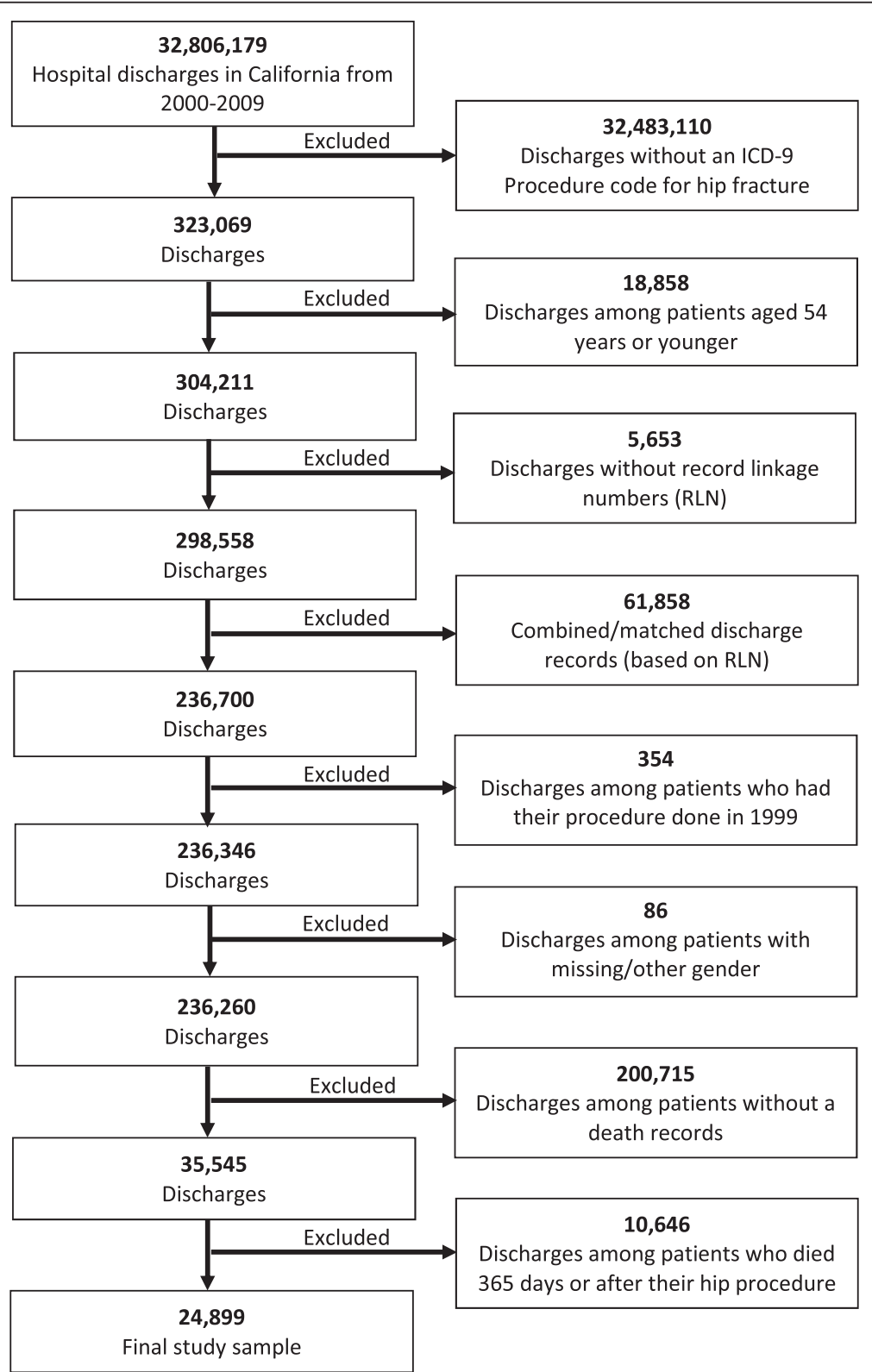

Fig. 2 Flow diagram to show the creation of the study sample for mortality after hip fractures 
as the reference group because this is the first group that is eligible for Medicare. Race/ethnicity had six levels: Caucasian, African American, Hispanic, Asian, Native American, and other. Caucasians were used as a reference group because they were the largest racial/ethnic subgroup (Table 1).

Rates were calculated by first calculating the count of hip fracture incidence in a relevant category. All analyses were weighted based on California population statistics, as described by the 2000 and 2010 US Census reports $[13,14]$. For all years between 2000 and 2010, census distributions were interpolated. In addition, all age rates were weighted by the proportion of each relevant age group in the population. This prevented rates from being inflated by high rates in groups with low absolute counts (e.g., the oldest age groups). Differences in the incidence and mortality rate of hip fractures, based on various subgroups, were evaluated using Poisson regression models. Odds ratios (OR) are provided with $95 \%$ confidence intervals (CI). All analyses were conducted in SPSS version 22 (Armonk, NY), Microsoft Excel (Redmond, WA), and R (Vienna, Austria).

Missing data were minimal for all analyses; cases with missing data were excluded from relevant analyses. Less than $3 \%$ of the sample were missing a social security number and had to be excluded from death rate calculations. All participants without gender information were excluded as all analyses were split by gender. All participants with gender information also had age information.

Table 1 Demographics

\begin{tabular}{ll}
\hline Demographic variable & $N(\%)$ \\
\hline Gender & \\
• Female & $229,212(72)$ \\
• Male & $88,465(28)$ \\
Age & \\
• $55-59$ & $11,367(3.6)$ \\
• 60-64 & $14,329(4.5)$ \\
• $65-69$ & $18,907(6.0)$ \\
• $70-74$ & $28,717(9.0)$ \\
• $75-79$ & $48,269(15.2)$ \\
• $80-84$ & $70,353(22.1)$ \\
• $85+$ & $125,735(39.6)$ \\
Race/ethnicity & \\
• Caucasian & \\
• Hispanic & $250,407(78.8)$ \\
• African American & $31,154(9.8)$ \\
• Native American & $8818(2.8)$ \\
• Asian & $473(0.1)$ \\
• Other & $16,811(5.3)$ \\
\hline
\end{tabular}

In addition, $1.6 \%$ of people had missing race/ethnicity data and were excluded from those analyses.

\section{Results}

\section{Hip fracture incidence}

All results were weighted using population rates from the US Census Bureau [13, 14] and are presented in Table 2. Hip fracture rates decreased over time (OR $0.98,95 \%$ CI $0.98,0.98, p<.001$, Fig. 3). Males were found to have a lower incidence of hip fractures than females (OR 0.46, $95 \%$ CI 0.46, 0.47, $p<.001$, Fig. 3). As gender differences were dramatic, all subsequent analyses were performed on males and females separately. As a person ages, they are more likely to sustain a hip fracture; females 85 years and above were 18.73 times more likely to sustain a hip fracture than those aged 6569 (95\% CI 18.36, 19.10, $p<.001)$. The relationship in males was even more dramatic, those 85 and above were 32.79 times more likely to sustain a hip fracture than the reference group (95\% CI 32.15, 33.43, $p<.001$; (Figs. 4 and 5). Caucasians had the highest incidence of hip fracture across all race/ethnicity groups; Native Americans had the lowest rates in reference to Caucasians (females OR 0.26, $95 \% \mathrm{CI}$ $0.24,0.29, p<.001$; males OR, 0.26, 95 \% CI 0.21 , $0.30, p<.001$, Figs. 6 and 7$)$.

Table 2 Adjusted odds ratio and $95 \%$ confidence intervals (95\% Cl) of gender, age group, and race/ethnicity in hip fracture patients from 2000-2011

\begin{tabular}{lll}
\hline Variable & & \\
\hline Year & $0.98[0.98,0.98]^{\mathrm{a}}$ & \\
\cline { 2 - 3 } Gemale & Male \\
\hline Gender & 1.00 & $0.46[0.98,0.98]^{\mathrm{a}}$ \\
Age group (years) & & \\
$55-59$ & $0.64[0.61,0.66]^{\mathrm{a}}$ & $0.66[0.64,0.69]^{\mathrm{a}}$ \\
$60-64$ & $0.61[0.60,0.62]^{\mathrm{a}}$ & $0.66[0.64,0.69]^{\mathrm{a}}$ \\
65-69 & 1.00 & 1.00 \\
$70-74$ & $1.92[1.88,1.95]^{\mathrm{a}}$ & $1.92[1.84,1.99]^{\mathrm{a}}$ \\
$74-79$ & $4.06[3.98,4.14]^{\mathrm{a}}$ & $4.62[4.53,4.71]^{\mathrm{a}}$ \\
$80-84$ & $10.70[10.49,10.91]^{\mathrm{a}}$ & $12.18[11.95,12.42]^{\mathrm{a}}$ \\
$85+$ & $18.73[18.36,19.10]^{\mathrm{a}}$ & $32.79[32.15,33.43]^{\mathrm{a}}$ \\
Race/ethnicity & & \\
Caucasian & 1.00 & 1.00 \\
Asian & $0.32[0.32,0.33]^{\mathrm{a}}$ & $0.32[0.30,0.33]^{\mathrm{a}}$ \\
African American & $0.35[0.35,0.36]^{\mathrm{a}}$ & $0.49[0.47,0.51]^{\mathrm{a}}$ \\
Hispanic & $0.39[0.39,0.40]^{\mathrm{a}}$ & $0.48[0.0,0.04]^{\mathrm{a}}$ \\
Native American & $0.26[0.24,0.29]^{\mathrm{a}}$ & $0.25[0.21,0.30]^{\mathrm{a}}$ \\
\hline a $p$ 0.001 & &
\end{tabular}




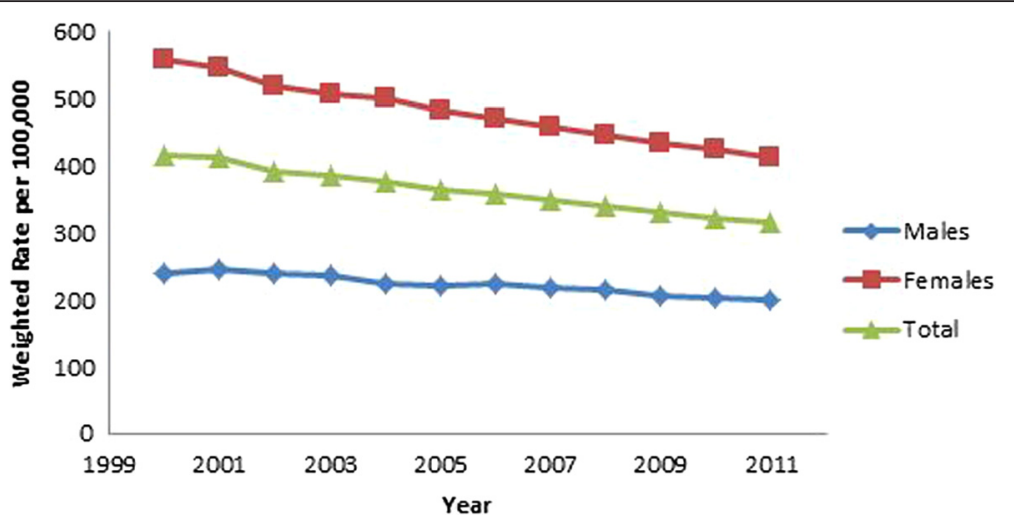

Fig. 3 Hip fracture incidence rates over time

\section{Hip fracture mortality}

All results were weighted using population rates from the US Census Bureau [13, 14]. Thirty, 90 and 365 day mortality results presented in Table 3. Over time, mortality rates decreased in both genders at 30-day post procedure (OR 0.97, $95 \%$ CI 0.96, 0.98, $p<.001$, Fig. 6), 90-day post procedure (OR 0.97, $95 \%$ CI $0.96,0.98, p<.001$ ), and 365 -day post procedure (OR 0.98, $95 \%$ CI 0.98, 0.98, $p<.001$, Fig. 6). Males were nearly two times more likely to die within 30 days of a procedure than females (OR 1.79, $95 \%$ CI 1.72, 1.86, $p<.001$ ) and were more likely to die at all assessed time points. Across all time mortality rate assessments, there were no differences in mortality rates for males between age groups 55-59, 60-64, and 64-69; however, females aged 55-59 had lower mortality rates than those aged 64-69 (OR 0.73, $95 \%$ CI $0.55,0.98, p<.05)$. For both genders, beyond age 69 , risk of death increased as a person aged. For both genders, Caucasians were more likely to die at 30, 90, and 365 days than all other races. Asians had the lowest mortality rates as compared to Caucasians (female, 30-day OR 0.59, $95 \%$ CI 0.51, 0.68, $p<.001$; male, 30-day OR, 0.62, $95 \%$ CI 0.52, 0.74, $p<.001$ ).

\section{Discussion}

Discussion of hip fracture incidence

There are multiple individual risks for the occurrence of a hip fracture including but not limited to osteoporosis, smoking, general health status, medical co-morbidities, exercise, and socio-economic status $[1,15]$. In this study, we found that Caucasian females, aged $85+$ were at the most risk for a hip fracture. Figure 3 (procedure rates over time) graphically illustrates the significant difference in hip fracture incidence with men having an incidence about half that of women. This study reports results consistent with similar studies done with Medicare data, European population studies, and previous studies on California data[1, 4, 16, 17]. When evaluating programs designed to reduce the incidence of hip

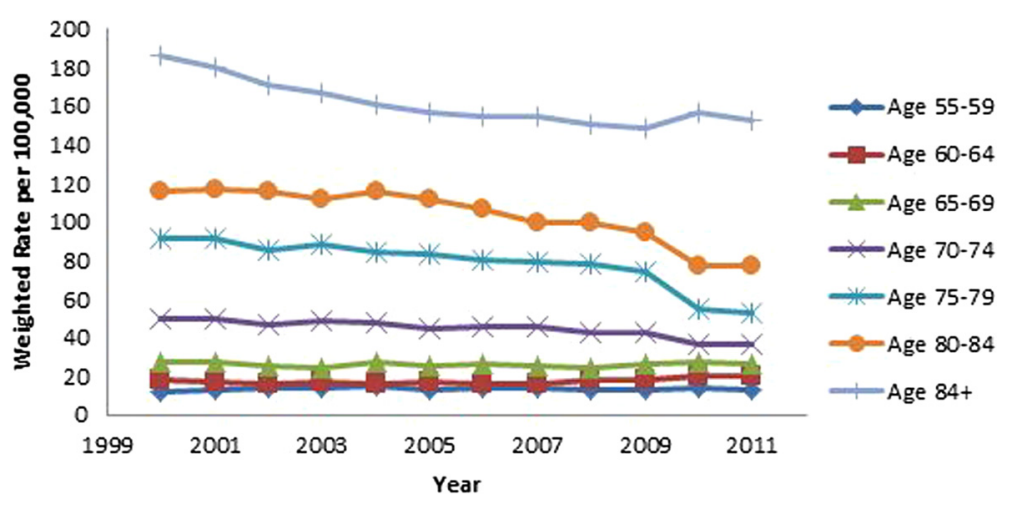

Fig. 4 Female hip fracture incidence rates over time, by age group 


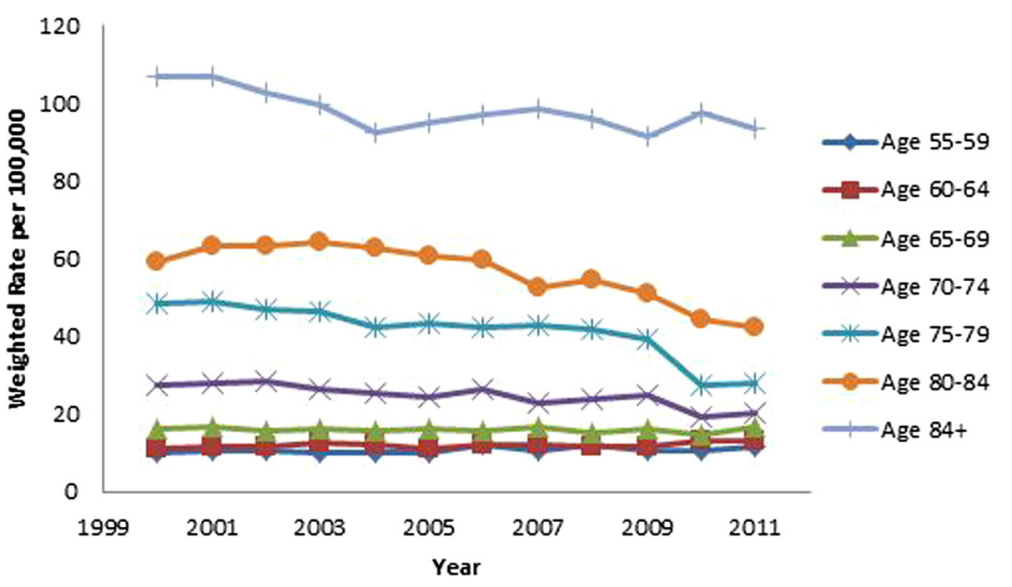

Fig. 5 Male hip fracture incidence rates over time, by age group

fractures the decreasing incidence must be factored into any program evaluation [16].

Figures 4 (female hip fracture rates over time) and 5 (male hip fracture rates over time) graphically illustrates that hip fracture incidence for men and women over the age of 70 declined over the study time period. These declines are an extension of the trend noted by Brauer et al. [1]. They suggest an improved trend for the overall California population in line with the Swiss population [18]. This improved trend may be partially explained by widespread prescription of bisphosphonate medications but improved population health, decreasing incidence of tobacco use and public health promotion of increased activity and healthy lifestyles are also possible contributors to this trend $[9,19,20]$. Kannus et al. [21] in agreement with this statement speculate that the biological basis for this declining rate is multifactorial.
Figures 6 (female hip fracture rates over time, by race/ ethnicity) and 7 (male hip fracture rates over time, by race/ethnicity) graphically illustrate that white men and women have a significantly higher incidence of hip fractures compared to the remainder of the population. The decline in incidence rate over the study time period has been more significant for white men and women.

Figure 6 (female hip fracture rates over time, by race/ ethnicity) is an interesting and consistent extension of Fig. 1a published in Zingmond et al. [8] for the period 1983-1998. The ethnic disparities are consistent with the data of Silverman and Madison from 1983-1984 [5]. When compared to Kanis et al., the data of the white population has an incidence rate similar to Sweden, Norway, Austria, and Ireland [22]. The remainder of the population has an incidence rate consistent with Spain, Mexico, and Chile, which are similar to a review done

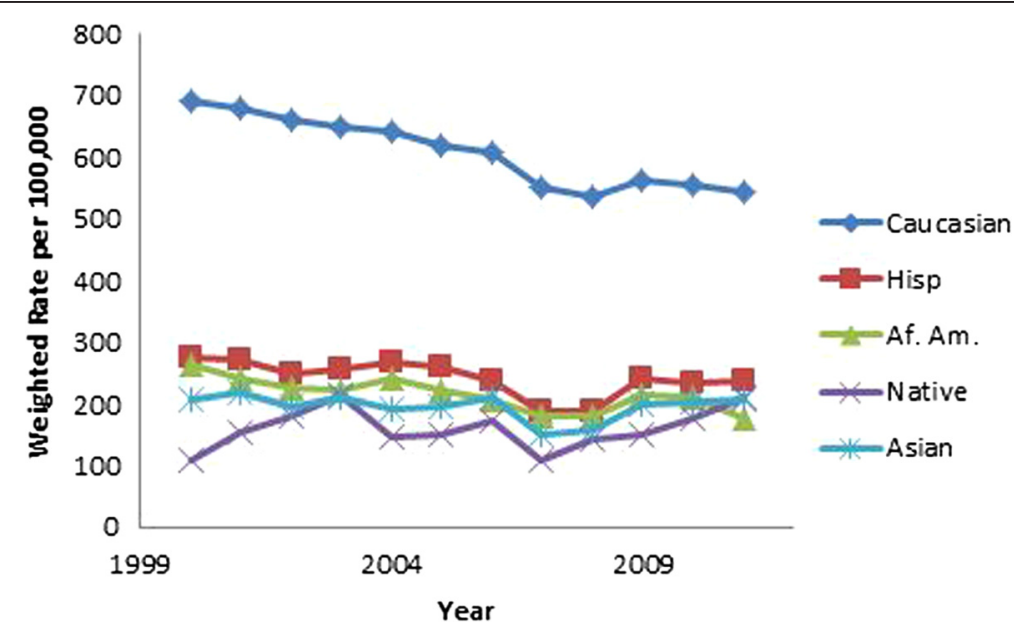

Fig. 6 Female hip fracture incidence rates over time, by race/ethnicity 


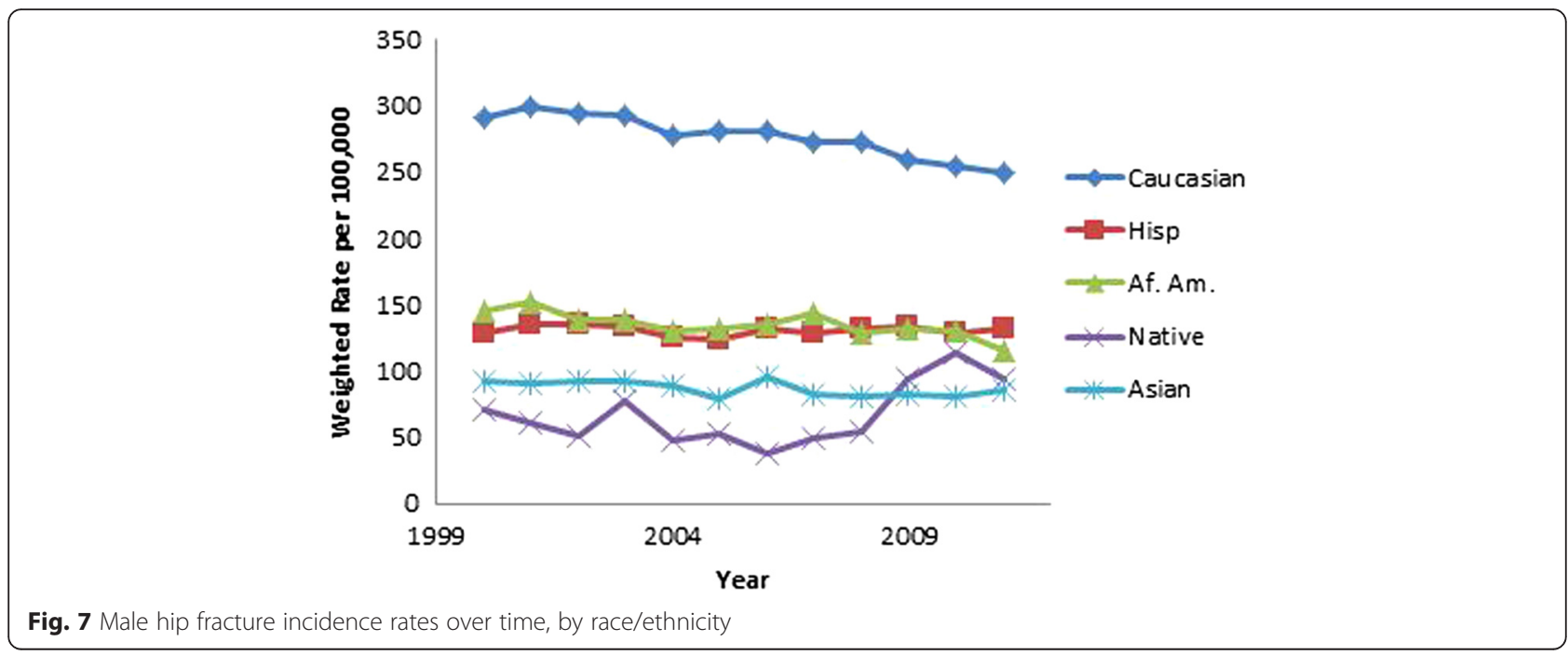

by Cheng et al. [23]. Wright et al. in a Medicare sample population found in a similar time period that incidence of Hispanic hip fractures had not declined, similar to our study [2]. Investigations of the race/ethnicity factor for hip fractures has been further confused by the changing demographics of the US population.

\section{Discussion of hip fracture mortality}

There are multiple individual risks for the occurrence of mortality following a hip fracture including but not limited to body pre-operative functional status, pre-operative cognitive status, congestive heart failure, general health status, diabetes, other medical comorbidities, and occurrence of post-operative patient complications (notably sepsis) [24, 25]. In this study, we found that Caucasian males aged $85+$ was the profile for patients at the most risk for a hip fracture mortality. That males were more likely than their female counterparts to die following a hip fracture was particularly interesting because females had the

Table 3 Adjusted odds ratio and $95 \%$ confidence intervals (95\% Cl) of gender, age group, and race/ethnicity in hip fracture patients from 2000-2009

\begin{tabular}{|c|c|c|c|c|c|c|}
\hline \multirow[b]{2}{*}{ Variable } & \multicolumn{2}{|l|}{ 30-day mortality } & \multicolumn{2}{|l|}{ 90-day mortality } & \multicolumn{2}{|l|}{ 365-day mortality } \\
\hline & & & & & & \\
\hline \multirow[t]{2}{*}{ Year } & \multicolumn{2}{|l|}{$0.97[0.96,0.98]^{a}$} & \multicolumn{2}{|l|}{$0.97[0.96,0.98]^{a}$} & \multicolumn{2}{|l|}{$0.98[0.98,0.98]^{a}$} \\
\hline & Female & Male & Female & Male & Female & Male \\
\hline Gender & 1.00 & $1.79[1.72,1.86]^{a}$ & 1.00 & $1.63[1.57,1.70]^{a}$ & 1.00 & $1.43[1.41,1.46]^{\mathrm{a}}$ \\
\hline \multicolumn{7}{|l|}{ Age group (years) } \\
\hline $55-59$ & $0.73[0.55,0.98]^{c}$ & $0.79[0.60,1.03]$ & $0.84[0.67,1.04]$ & $0.70[0.56,0.89]^{b}$ & $0.96[0.81,1.15]$ & $0.74[0.61,0.90]^{b}$ \\
\hline $60-64$ & $0.87[0.67,1.21]$ & $0.95[0.74,1.23]$ & $0.89[0.73,1.08]$ & $0.98[0.81,1.19]$ & $0.99[0.85,1.16]$ & $0.99[0.83,1.18]$ \\
\hline $65-69$ & 1.00 & 1.00 & 1.00 & 1.00 & 1.00 & 1.00 \\
\hline $70-74$ & $1.18[0.97,1.44]$ & $1.60[1.29,1.98]^{a}$ & $1.20[1.02,1.40]^{c}$ & $1.45[1.21,1.72]^{a}$ & $1.30[1.15,1.46]^{\mathrm{a}}$ & $1.39[1.21,1.60]^{\mathrm{a}}$ \\
\hline $75-79$ & $1.49[1.25,1.78]^{a}$ & $2.20[1.81,2.68]^{a}$ & $1.43[1.25,1.64]^{a}$ & $1.99[1.70,2.33]^{a}$ & $1.54[1.37,1.73]^{a}$ & $1.86[1.62,2.13]^{a}$ \\
\hline $80-84$ & $1.73[1.48,2.02]^{\mathrm{a}}$ & $2.61[2.18,3.11]^{\mathrm{a}}$ & $1.80[1.57,2.07]^{\mathrm{a}}$ & $2.41[2.10,2.77]^{\mathrm{a}}$ & $1.95[1.74,2.20]^{\mathrm{a}}$ & $2.32[2.06,2.61]^{a}$ \\
\hline $85+$ & $3.25[2.78,3.81]^{a}$ & $4.22[3.54,5.03]^{a}$ & $3.32[2.95,3.73]^{a}$ & $3.71[3.23,4.25]^{a}$ & $3.56[3.23,3.93]^{a}$ & $3.42[3.04,3.85]^{\mathrm{a}}$ \\
\hline \multicolumn{7}{|l|}{ Race/ethnicity } \\
\hline Caucasian & 1.00 & 1.00 & 1.00 & 1.00 & 1.00 & 1.00 \\
\hline Asian & $0.59[0.51,0.68]^{a}$ & $0.62[0.52,0.74]^{\mathrm{a}}$ & $0.52[0.46,0.58]^{\mathrm{a}}$ & $0.59[0.51,0.68]^{\mathrm{a}}$ & $0.51[0.46,0.56]^{\mathrm{a}}$ & $0.57[0.51,0.64]^{\mathrm{a}}$ \\
\hline African American & $0.78[0.67,0.91]^{c}$ & $0.64[0.53,0.78]^{a}$ & $0.78[0.68,0.89]^{a}$ & $0.66[0.56,0.79]^{a}$ & $0.73[0.65,0.82]^{a}$ & $0.73[0.63,0.83]^{\mathrm{a}}$ \\
\hline Hispanic & $0.79[0.71,0.87]^{a}$ & $0.68[0.61,0.77]^{\mathrm{a}}$ & $0.71[0.66,0.77]^{\mathrm{a}}$ & $0.66[0.60,0.72]^{a}$ & $0.66[0.63,0.70]^{\mathrm{a}}$ & $0.65[0.60,0.70]^{a}$ \\
\hline
\end{tabular}




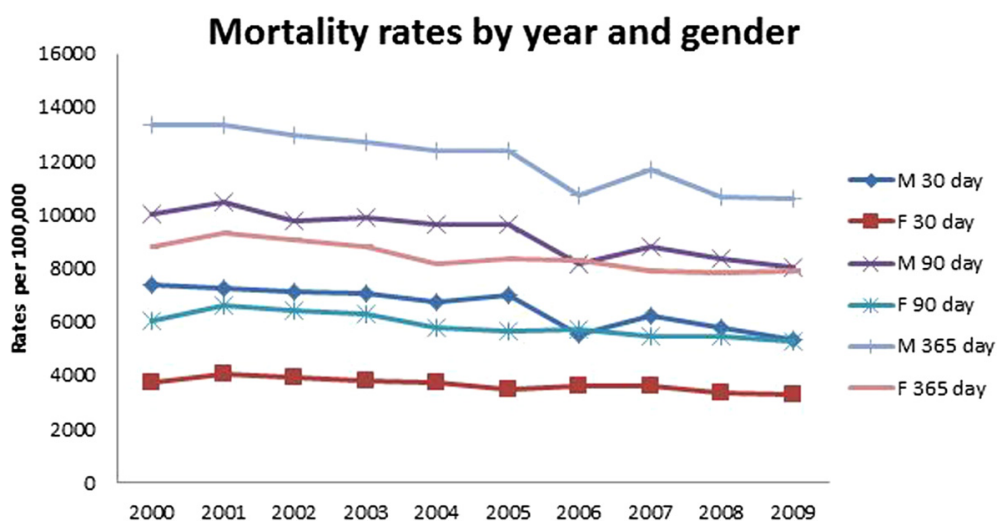

Fig. 8 30-, 90-, and 365-day mortality rates over time

highest hip fracture incidence rates. The increase in mortality risk associated with increasing age and male gender has been widely noted in other studies of this topic [7, 26-28].

Figure 8 (30-, 90-, and 365-day mortality rates over time) graphically illustrates that all mortality rates decreased over the study time period. This is a resumption of a trend to decreased mortality that Brauer et al. noted had stalled in about 1998 [1].

Figures 9 and 10 graphically illustrate that the incidence of 30-day mortality varies by decade of life for both men and women. These gender- and age-specific baseline mortality rates will be helpful to risk adjust the incidence of mortality after hip fracture care. Mortality rates are being introduced in the USA and elsewhere as a quality measure for hip fracture care [11]. There has been an increase in the use of systematic interventions including co-operative care between surgeons and medical practitioners, attention to pain management, delirium prevention, early surgery, and aggressive mobilization [29-32].

Penrod et al. in a study of approximately 3000 patients from 1997-1999 found that white patients enjoyed a mortality risk advantage compared to the rest of the study population [25]. Our study was based on a much larger and more comprehensive study population. Sterling documented a gap in the literature with regard to racial and ethnic differences in the survival of US hip fracture patients [33]. A more current literature search has failed to find current studies on this topic. One older citation was based on a very different racial/ethnic population compared to 2009 [3].

\section{Limitations}

One limitation was that we selected our dataset based on the principal procedure code only. Other procedure codes are recorded, and so there is a possibility that we

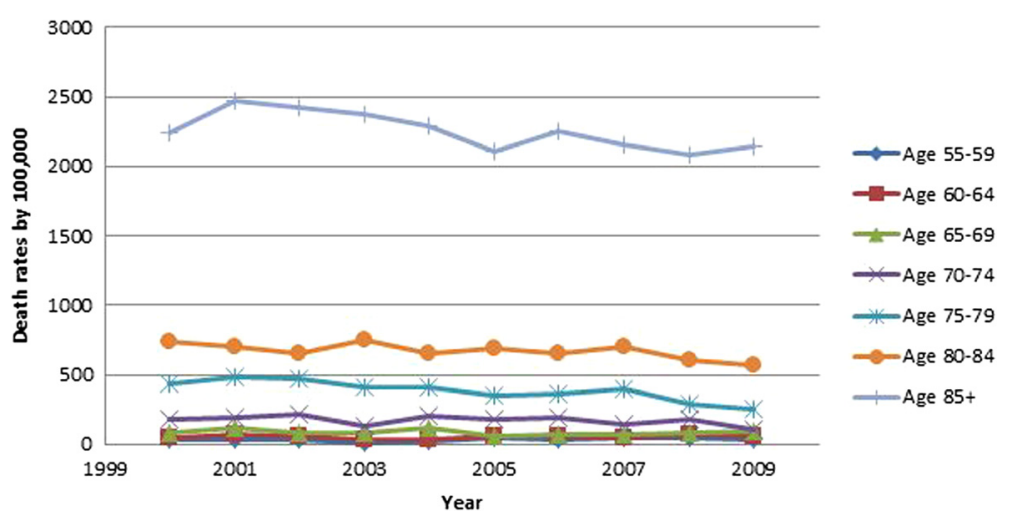

Fig. 9 Female 30-day mortality rates over time, by age 


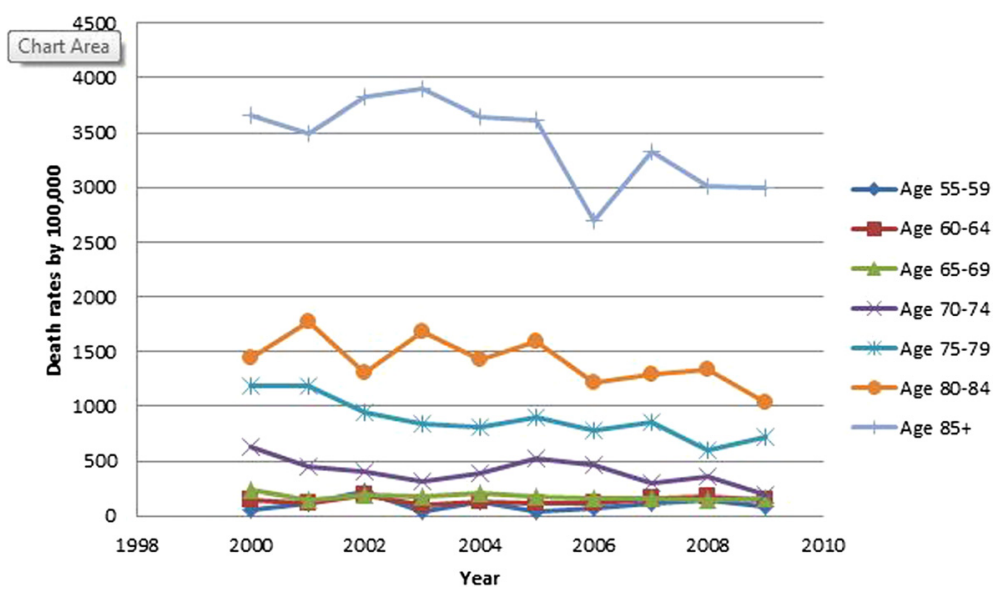

Fig. 10 Male 30-day mortality rates over time, by age

missed some patients who had a hip fracture that was not coded as their principal procedure. This is ICD-9 data and laterality is not a data element.

Although the patient data record contains information regarding the hospital where the surgery occurred, there is no data with regard to transfers of patients for admission, subsequent re-operations at a second hospital for the same fracture, nor data with regard to the individual attending surgeon. These factors would all be useful information for the analysis [34, 35].

Another limitation is the inadvertent inclusion of a small group of patients $(n=296)$ who had a principal procedure code of 79.55 (open reduction of separated epiphysis, femur) and were older than age 55 . Since this is a pediatric orthopedic procedure, this combination of principal procedure code and age is likely the result of incorrect coding at the hospital level. However, it is unknown if the incorrect coding was in the age of the patient or the principal procedure code. The number of patients is small (0.09\%), data analysis was not re-done, and inclusion of this subset should not significantly affect the results.

The last important limitation of using the OSHPD dataset was the lack of important clinical risk data (e.g., smoking status, substance abuse status, socioeconomic status information, opioid use, pre-operative mobility, and cognitive status, etc.) $[1,15]$. Due to the nature of the dataset, there was no way to analyze any of these factors and therefore we must accept this limitation of applying these results to health effectiveness research.

\section{Conclusion}

This California state-wide population-based study of a large and diverse population shows a significant reduction in hip fracture incidence over the study period of 2000-2011 and a corresponding reduction in mortality over the study period of 2000-2009. There are significant gender, age, race/ethnicity disparities for both hip fracture incidence and mortality in subpopulations that will allow for targeted population interventions and opportunities for further research. Further, these data will provide baseline information to assess and risk stratify outcomes and interventions.

\section{Ethics approval}

IRB approval was received from Community Medical Center (\#2012094) and the State of California's Committee for the Protection of Human Subjects (\#12-10-0840).

\section{Competing interests}

The authors declare that they have no competing interests.

\section{Authors' contributions}

KS provided oversight on all statistical analysis and results write up and is the lead author of the manuscript. LH coordinated the project, literature review, manuscript preparation, and submission. MA assisted with data cleaning and statistical analysis. WTB provided oversight on the entire project, literature review, and manuscript preparation. All authors read and approved the final manuscript.

\section{Funding}

No external funding was received in support of this investigation.

\section{Author details}

${ }^{1}$ Psychological Science, UC Merced, 5200 Lake Road, Merced, CA 95343, USA. ²Orthopaedic Surgery, UCSF-Fresno, 155 N Fresno Street, Fresno, CA 93701, USA. ${ }^{3}$ Orthopaedic Surgery, Kaiser Permanente Medical Center, $7300 \mathrm{~N}$ Fresno Street, Fresno, CA 93720, USA.

Received: 2 October 2015 Accepted: 4 December 2015

Published online: 08 January 2016

\section{References}

1. Brauer CA, Coca-Perraillon M, Cutler DM, Rosen AB. Incidence and mortality of hip fractures in the United States. JAMA. 2009;302(14):1573-9. 
2. Wright NC, Saag KG, Curtis JR, Smith WK, Kilgore ML, Morrisey MA, et al. Recent trends in hip fracture rates by race/ethnicity among older US adults. J Bone Miner Res. 2012;27(11):2325-32.

3. Jacobsen SJ, Goldberg J, Miles TP, Brody JA, Stiers W, Rimm AA. Race and sex differences in mortality following fracture of the hip. Am J Public Health. 1992:82(8):1147-50.

4. Lonnroos E, Kautiainen H, Karppi P, Huusko T, Hartikainen S, Kiviranta I, et al. Increased incidence of hip fractures. A population based-study in Finland. Bone. 2006;39(3):623-7.

5. Silverman SL, Madison RE. Decreased incidence of hip fracture in Hispanics, Asians, and blacks: California Hospital discharge data. Am J Public Health. 1988;78(11):1482-3.

6. Haleem S, Lutchman L, Mayahi R, Grice JE, Parker MJ. Mortality following hip fracture: trends and geographical variations over the last 40 years. Injury. 2008;39(10):1157-63.

7. Endo Y, Aharonoff GB, Zuckerman JD, Egol KA, Koval KJ. Gender differences in patients with hip fracture: a greater risk of morbidity and mortality in men. J Orthop Trauma. 2005;19(1):29-35.

8. Zingmond DS, Melton 3rd LJ, Silverman SL. Increasing hip fracture incidence in California Hispanics, 1983 to 2000. Osteoporos Int. 2004;15(8):603-10.

9. Fisher A, Martin J, Srikusalanukul W, Davis M. Bisphosphonate use and hip fracture epidemiology: ecologic proof from the contrary. Clin Interv Aging. 2010:5:355-62.

10. Dhanwal DK, Dennison EM, Harvey NC, Cooper C. Epidemiology of hip fracture: worldwide geographic variation. Indian J Orthop. 2011;45(1):15-22.

11. Hyder JA, Roy N, Wakeam E, Hernandez R, Kim SP, Bader AM, et al. Performance measurement in surgery through the National Quality Forum. J Am Coll Surg. 2014;219(5):1037-46.

12. Zingmond DS, Ye Z, Ettner SL, Liu H. Linking hospital discharge and death records_-accuracy and sources of bias. J Clin Epidemiol. 2004;57(1):21-9.

13. US Dicennial Census of Population and Housing 2000 [http://www.census. gov/main/www/cen2000.html]

14. US Dicennial Census of Population and Housing 2010 [http://www.census. gov/2010census/]

15. Marks R. Hip fracture epidemiological trends, outcomes, and risk factors, 1970-2009. Intl J Gen Med. 2010;3:1-17.

16. Adams AL, Shi J, Takayanagi M, Dell RM, Funahashi TT, Jacobsen SJ, Ten-year hip fracture incidence rate trends in a large California population, 1997-2006. Osteoporos Int. 2013;24(1):373-6.

17. Cooper C, Cole ZA, Holroyd CR, Earl SC, Harvey NC, Dennison EM, et al. Secular trends in the incidence of hip and other osteoporotic fractures. Osteoporos Int. 2011;22(5):1277-88.

18. Chevalley T, Guilley E, Herrmann FR, Hoffmeyer P, Rapin CH, Rizzoli R. Incidence of hip fracture over a 10-year period (1991-2000): reversal of a secular trend. Bone. 2007:40(5):1284-9.

19. Fisher AA, O'Brien ED, Davis MW. Trends in hip fracture epidemiology in Australia: possible impact of bisphosphonates and hormone replacement therapy. Bone. 2009;45(2):246-53.

20. Abrahamsen $B$, Vestergaard P. Declining incidence of hip fractures and the extent of use of anti-osteoporotic therapy in Denmark 1997-2006. Osteoporos Int. 2010;21(3):373-80.

21. Kannus P, Niemi S, Parkkari J, Palvanen M, Vuori I, Jarvinen M. Nationwide decline in incidence of hip fracture. J Bone Miner Res. 2006;21(12):1836-8.

22. Kanis JA, Oden A, McCloskey EV, Johansson H, Wahl DA, Cooper C, et al. A systematic review of hip fracture incidence and probability of fracture worldwide. Osteoporos Int. 2012;23(9):2239-56.

23. Cheng SY, Levy AR, Lefaivre KA, Guy P, Kuramoto L, Sobolev B. Geographic trends in incidence of hip fractures: a comprehensive literature review. Osteoporos Int. 2011;22(10):2575-86.

24. Hernandez JL, Olmos JM, Alonso MA, Gonzalez-Fernandez CR, Martinez J, Pajaron $\mathrm{M}$, et al. Trend in hip fracture epidemiology over a 14-year period in a Spanish population. Osteoporos Int. 2006;17(3):464-70.

25. Penrod JD, Litke A, Hawkes WG, Magaziner J, Doucette JT, Koval KJ, et al, The association of race, gender, and comorbidity with mortality and function after hip fracture. J Gerontol A Biol Sci Med Sci. 2008;63(8):867-72.

26. Holt G, Smith R, Duncan K, Hutchison JD, Gregori A. Gender differences in epidemiology and outcome after hip fracture: evidence from the Scottish Hip Fracture Audit. J Bone Joint Surg. 2008;90-B(4):480-3.

27. Holt G, Smith R, Duncan K, Hutchison JD, Reid D. Changes in population demographics and the future incidence of hip fracture. Injury. 2009;40(7):722-6.
28. Pugely AJ, Martin CT, Gao Y, Klocke NF, Callaghan JJ, Marsh JL. A risk calculator for short-term morbidity and mortality after hip fracture surgery. J Orthop Trauma. 2014;28(2):63-9.

29. Friedman SM, Mendelson DA, Bingham KW, Kates SL. Impact of a comanaged Geriatric Fracture Center on short-term hip fracture outcomes. Arch Intern Med. 2009;169(18):1712-7.

30. Hung WW, Egol KA, Zuckerman JD, Siu AL. Hip fracture management: tailoring care for the older patient. JAMA. 2012;307(20):2185-94.

31. Ibrahim MS, Twaij H, Giebaly DE, Nizam I, Haddad FS. Enhanced recovery in total hip replacement: a clinical review. Bone Joint J. 2013;95-b(12):1587-94.

32. Lau TW, Fang C, Leung F. The effectiveness of a geriatric hip fracture clinical pathway in reducing hospital and rehabilitation length of stay and improving short-term mortality rates. Geriatr Orthop Surg Rehabil. 2013:4(1):3-9.

33. Sterling RS. Gender and race/ethnicity differences in hip fracture incidence, morbidity, mortality, and function. Clin Orthop Relat Res. 2011:469(7):1913-8.

34. Kristoffersen DT, Helgeland J, Clench-Aas J, Laake P, Veierod MB. Comparing hospital mortality - how to count does matter for patients hospitalized for acute myocardial infarction (AMI), stroke and hip fracture. BMC Health Serv Res. 2012;12:364.

35. Kristensen PK, Thillemann TM, Johnsen SP. Is bigger always better? A nationwide study of hip fracture unit volume, 30-day mortality, quality of in-hospital care, and length of hospital stay. Med Care. 2014;52(12):1023-9.

\section{Submit your next manuscript to BioMed Central and we will help you at every step:}

- We accept pre-submission inquiries

- Our selector tool helps you to find the most relevant journal

- We provide round the clock customer support

- Convenient online submission

- Thorough peer review

- Inclusion in PubMed and all major indexing services

- Maximum visibility for your research

Submit your manuscript at www.biomedcentral.com/submit
) Biomed Central 